\title{
UN CASO DE EDITORIAL INDEPENDIENTE EN AMÉRICA LATINA ENTREVISTA A FABIÁN LEBENGLIK, DIRECTOR EDITORIAL DE ADRIANA HIDALGO EDITORIAL, 29 DE SEPTIEMBRE DE 2009
}

\footnotetext{
Mirna Soares Andrade* é mestranda em Estudos da Linguagem na PUC-Rio. E-mail: mirnasoares@yahoo.com
}

Em um bairro elegante de Buenos Aires encontrei a pequena grande Editora Adriana Hidalgo. Fundada em 1999 em reação à dominação estrangeira do mercado editorial argentino, desde o início manifestou suas ambições cosmopolitas: apresentar a literatura mundial ao público leitor em todos os países de língua espanhola. A modesta tiragem da maioria das publicações não traduz o alcance da circulação de seus livros, que podem ser encontrados em livrarias da Argentina, Chile, Peru, México e até mesmo Espanha.

Estar sediada em uma capital que ostenta uma impressionante quantidade de livrarias per capita é um tempero a mais na receita desse projeto levado adiante por Adriana Hidalgo Solá, responsável pela direção geral, e Fabian Lebenglik, diretor e editor da empresa. A rotina de Fabian consiste no que ele qualifica como um trabalho fascinante: ler bons livros e descobrir novos escritores talentosos. Sua mesa repleta de manuscritos se harmoniza com as estantes carregadas de obras já publicadas. Dentre elas Descubrimientos, de Clarice Lispector, Dónde andará Dulce Veiga, de Caio Fernando Abreu, El dia de las ratas, de Dyonélio Machado, A cielo abierto, de João Gilberto Noll e Gran sertón: Veredas, de Guimarães Rosa.

Foi a recente publicação desta última, em 2009, que me levou até ali. O interesse pela tradução, a recepção da literatura brasileira no exterior e o papel de uma editora na formação de um público leitor guiou minha conversa com Fabian Lebenglik.

$* * *$

\section{¿Cuándo y cómo surgió Adriana Hidalgo Editorial?}

El primer libro lo publicamos en Septiembre de 1999. Así que decimos que es la última editorial independiente del siglo XX. Surgió en parte porque Adriana Hidalgo era una de las directoras de la El Ateneo, una editorial centenaria que su abuelo español había fundado en Buenos Aires. Y en parte también surgió porque yo he trabajado toda la vida en editoriales, entre ellas en El Ateneo, donde conocí a Adriana Hidalgo. Cuando El Ateneo, por cuestiones familiares se disgrega y es vendida a otro grupo editorial y económico, con Adriana decidimos fundar un editorial propia, artesanal, pequeña. Era un momento en el que Argentina estaba transnacionalizando todos sus sellos editoriales. No quedaban ya sellos argentinos, habían sido comprados por grandes grupos económicos y editoriales

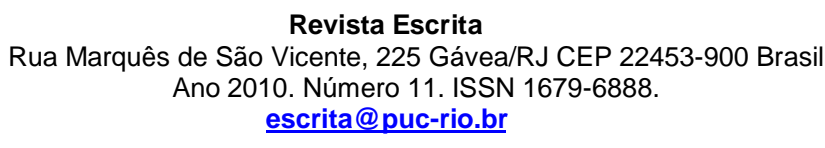


internacionales y entonces todas las decisiones editoriales, estratégicas y de políticas culturales en el plano literario se tomaban fuera de Argentina. Entonces, una editorial argentina que era subsidiaria de una gran firma editorial internacional no podía prácticamente tomar decisiones propias. Nos pareció que había llegado el momento de fundar una editorial que tuviera grandes aspiraciones en cuanto a la calidad de aquello que publicara y que al mismo tiempo respondiera a la historia editorial de independencia que tiene la Argentina.

\section{¿Qué quiere decir una editorial independiente?}

Independiente de los gobiernos, del lucro como objetivo central e independiente de los grandes grupos editoriales y económicos. La finalidad de una editorial independiente no es la avidez económica y de dinero, sino la de publicar buenos libros y, como consecuencia de eso, la editorial se iba a sostener y se está sosteniendo, publicando buena literatura. La tradición literaria argentina de editoriales independientes ha sido muy fuerte. En España hubo muchos años de dictadura de Franco, desde 1936 hasta 1975, cuando muere Franco la mayoría de la mejor literatura se publicaba desde Argentina. No solamente eso, la Argentina también fue pionera en publicar la primera traducción de prácticamente toda la gran literatura extranjera. Es decir que cuando un escritor italiano, ruso, francés, norteamericano, inglés o alemán publicaba un libro, la primera traducción fuera de su país de origen era realizada en Argentina. Gracias a grandes lectores como Borges o José Bianco, así como tantos otros grandes escritores- traductores- lectores de primer nivel, o de revistas literarias y editoriales independientes que publicaban todo eso. Tratamos un poco de seguir esa tradición cuando estaba declinando el mundo editorial argentino. Este resurgimiento editorial fue como una especie de flor en el desierto.

\section{¿Cómo es un proceso típico de publicación de un libro?}

El input es variado. Puede ser una ocurrencia propia. A veces puede ser una idea nuestra o también puede suceder que alguien nos acerque una idea. Leemos mucho, evaluamos cada libro y así vamos avanzando. En algunos casos contamos con lectores en los cuales confiamos. Si el libro nos gusta muchísimo, lo publicamos. Todos los que hemos publicado hasta ahora fueron elegidos porque responden a nuestro gusto, no hacemos concesiones. No tenemos a priori una preferencia por géneros: publicamos poesía, ensayo, novela, ficción de todo tipo, no ficción, arte, música, teatro... Si es muy bueno y está bien escrito... lo publicamos.

\section{¿Hay una investigación de mercado o se consideran otros factores además de gustar de un libro?}

No. Por ejemplo, nosotros publicamos hace dos o tres años a una escritora alemana. Vimos el original y nos pareció maravilloso. Se llama Katja Lange-Müller. De ella publicamos una

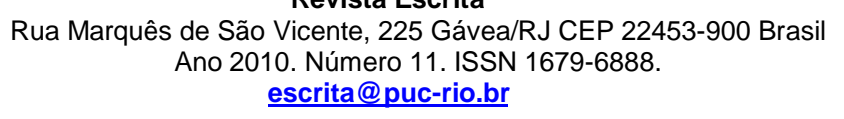


novela cuyo título traducido es Los últimos. Nos gustó muchísimo el libro. Apenas se publicó su siguiente novela, compramos los derechos para publicarla. Sucedió que esa novela vendió decenas de miles de ejemplares en Europa y luego todos querían publicarla en lengua castellana, pero los derechos los teníamos nosotros. No hicimos una investigación de mercado previa.

Otro caso, llega a nuestras manos un libro maravilloso que nos gustó mucho de un escritor extranjero, decidimos publicarlo. Por otra parte, la embajada del país de origen del escritor, lo invitó a Argentina pare presentar el libro. El escritor vino, presentó ante una enorme cantidad de público y poco después sucedió que ese autor, Le Clézio, ganó el premio Nobel de Literatura. Eso nos catapultó de una manera extraordinaria. Le Clézio vino a la Argentina a presentar El africano y ahora podría decirse que en la lengua castellana al ganador del Nobel 2008 se lo conoce como "El autor de El Africano" (que Cosac Naify publicó en Brasil). No hicimos cálculos de mercado, porque de hecho era un autor que no vendía mucho. El propio Le Clézio trabó relación personal con nosotros, quedó encantado con la traducción (habla muy bien el castellano), realizada por la poeta y traductora argentina Juana Bignozzi y entonces continuamos la relación: publicamos su nueva novela, La música del hambre y vamos a publicar varios libros más de él. A nosotros nos gustó, lo publicamos y fuimos los editores del premio Nobel. Creo que se trata de una mezcla de olfato, intuición y buena suerte. Pensamos que buscando la calidad, lo demás llega por añadidura.

\section{¿Cómo se diferencian las colecciones?}

Tenemos la concepción de que una editorial es una guía de lectura, una especie de biblioteca. Entonces las colecciones suponen darle un cauce a las diferentes lecturas y libros. Como si fuera el cauce de un río, a cada grupo de libros se le asigna una relación con libros que fueron publicados antes o con otros que van a ser publicados después, en una misma colección. Una colección supone una relación mínima e indispensable entre un libro y otro, a veces se relacionan con la temática o por el tratamiento literario. Las colecciones son convencionales, artificiales, por supuesto. Un modo de incidir sobre la lectura y dar una guía al lector. Así el lector sabe que esa colección tiene una personalidad determinada. Publicamos ese último de Le Clézio y otro anterior en una colección donde también está Clarice Lispector, o Jack Jerouac, Herman Broch, Caio Fernando Abreu, Guimaraes Rosa o Witold Gombrowicz... y así vamos armando una serie, una colección

\section{¿Las tapas tienen el mismo proyecto gráfico?}

Sí, la colección mencionada ("Narrativas") reúne a grandes narradores en lenguas extranjeras. Tenemos allí cuatro novelas de João Gilberto Noll, por ejemplo. Uno de los suplementos literarios más importantes que hay aquí, el del Diario Perfil, publicó

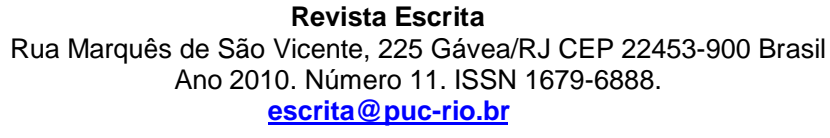


recientemente una nota bajo el título "Euforia Gráfica" y se refería a los libros, pero especialmente a las tapas, de las cuatro novelas de Noll. Allí se menciona que de sólo ver esas tapas (que por otra parte son tipográficas) da ganas de comprar el libro y que, además, Noll es lo más maravilloso que el reseñista leyó últimamente...

\section{¿Son publicados escritores nuevos? \\ Sí, publicamos autores nuevos no solamente en castellano sino también en otras lenguas.}

\section{¿Estas publicaciones son el resultado de investigaciones específicas en la búsqueda de} nuevos escritores?

Sí, tenemos una formación literaria universitaria y combinamos lecturas académicas con otras absolutamente no académicas o decididamente antiacadémicas. Buscamos ciertos libros, escuchamos consejos acerca de otros, seguimos recomendaciones, leemos todo el tiempo.

Hablaste de muchas traducciones. ¿Ellas representan una gran parte de los libros publicados?

Como decía al comienzo de la entrevista, tratamos de seguir la tradición argentina en ediciones independientes. Argentina, sobretodo Buenos Aires, es muy cosmopolita y continuamos con esta idea: la mitad de nuestros libros son de autores argentinos o latinoamericanos y la otra mitad son traducciones. Traducciones que hemos hecho hasta ahora de manera directa del japonés, irlandés, alemán, francés, italiano, hebreo, sueco, portugués, ruso, polaco. De la lengua que sea, si nos interesa y podemos contar con una traducción confiable, lo publicamos. Si es joven y nos gusta, lo publicamos también. Y si es una novela o un libro consagrado, pero que fue olvidado o aún está inédito, también... Es el caso de Os ratos, de Dyonélio Machado: obviamente no es nuevo, ya murió, pero es una novela extraordianria y nos parece que merece ser leída por los lectores en lengua castellana.

\section{¿Qué escritores brasileños fueron publicados?}

João Gilberto Noll, Clarice, Caio Fernando Abreu, Guimarães Rosa, Manuel Bandeira, Dyonélio Machado, Haroldo de Campos. Y seguiremos con muchos autores más de Brasil.

\section{¿Cómo es la recepción del público argentino con respecto a la literatura brasileña?}

Antes me preguntabas sobre el mercado y ese no es un tema que me interese particularmente. No me ocupo de eso, me ocupo de los contenidos. Los lectores no solamente se van a buscar, también se crean nuevos lectores. Se puede crear lectores. Es difícil la recepción de la literatura brasileña en general, porque hay en la Argentina un cierto grado de colonización cultural, según la cual se lee más literatura anglosajona. Pero 
Brasil tiene una enorme literatura y si voy a guiarme por los gustos del público no debería publicar literatura brasileña. Sin embargo es una gran literatura y lo que falta es mayor contacto y frecuentación. Hay muchísima literatura brasileña todavía sin traducir y que permanece como poco conocida. Adoro Brasil, su cultura es central para mí: no solo literaria, sino también en las artes plásticas, la música y el cine. Me parece que no puede faltar eso y con entusiasmo hay que convencer y contagiar el entusiasmo a los lectores. De a poco se comienza. Acabamos de publicar por ejemplo una nueva traducción de Grande Sertão y los lectores están respondiendo bien. En América del Sur, en España y en México. Una característica de nuestra editorial es que todo lo que publicamos, lo hacemos para todo el territorio mundial de la lengua castellana. Nuestros libros se distribuyen y venden en Argentina, en España, México, Chile, Uruguay, Colombia... en toda América latina.

\section{La lengua produce un aislamiento de Brasil. ¿Qué otros factores te parece que prevalecen?}

Hay algo muy particular. Voy todos los años a la feria de Frankfurt, precisamente mañana salgo de viaje para España y después para Frankfurt, a la feria. Los derechos de traducción una parte importante de los autores brasileños son manejados por una agencia literaria alemana que fundó una gran agente: Ray-Güde Mertin que falleció hace dos años. Su contacto fuerte y directo sucedió cuando ella dirigió el instituto Goethe de Rio de Janeiro. Ella se contactó con lo mejor de la literatura brasilera del momento y cuando terminó su cargo, vuelve a Alemania y se hace agente literaria. Empieza a representar los derechos de traducción de los escritores en lengua portuguesa. Su agencia también representa a Saramago y a otros escritores portugueses y angoleñosa. Para publicar lo mejor y más importante de la literatura brasilera, inclusive a Guimarães Rosa, hay que gestionar los derechos con una agencia alemana.

Hace dos años, Adriana Hidalgo publicó Sagarana y en Junio de este año Gran Sertón: Veredas. ¿Cuál es el por qué del interés renovado por Guimarães Rosa?

Es un escritor fundamental, no sólo para la literatura en Brasil, sino también latinoamericana y de toda la literatura moderna. Nos parecía que hacía tanto tiempo que estaba un poco olvidado fuera de Brasil, que requería una nueva traducción. Porque una traducción es una lectura de época, quien traduce, traduce también sus conocimientos y sus puntos así como sus interpretaciones implícitas y eso marca una sincronía con determinada época. Toda traducción envejece, en general. Nos pareció que era necesaria una nueva traducción, además hecha con una proximidad especial, porque la única que había era de Angel Crespo, un poeta español y tenía que haber una traducción desde América Latina, donde por cuestiones de vecindad, procesos culturales e históricos, se comprenden aún mejor los giros e innovaciones de Guimaraes Rosa. Los traductores de la nueva versión al castellano son los argentinos Florencia Garramuño y Gonzalo Aguilar. 


\section{¿Quiénes son los autores best-sellers en Argentina?}

En general el best-seller tiene que ver con una máquina mercantil, mercadotécnica, que escapa un poco a nuestros modos de producir los libros. Pero nuestro catálogo está todo "vivo", tenemos un fondo editorial que los lectores saben apreciar y además de publicar 22 libros al año, publicamos unas veinte reimpresiones por año: esto habla de campo de interés amplio y que va bien, y al mismo tiempo, afortunadamente, todavía nos falta mucho por recorrer.

\section{¿Y los autores que venden más?}

Todos ellos se venden. Nosotros no jugamos con el tema de gran venta inicial, sino con la gran venta sostenida en el tiempo de todo nuestro fondo editorial. Es así con libros que editamos desde que surgió la editorial y que seguimo publicando diez años despues, en su sexta o séptima edición. Nos pasó obviamente con Le Clézio, cuando vendimos unos cuantos miles de ejemplares muy rápidamente, porque un premio Nobel es muy requerido por el mercado. Nuestros libros, todos se venden. Y hacemos ediciones de 2 mil a 3 mil ejemplares, salvo excepciones de 5 mil.

\section{¿Cómo caracterizaría al lector argentino?}

Diría que hay varios tipos de lectores. En general, pienso en un lector parecido a mí. Cosmopolita, ávido, que quiere leer todo lo que puede, al que le interesan muchos temas... y en este sentido tenemos lectores fieles que siguen al sello editorial. Se publica algo en la editorial y van a comprar el libro. Pero el mercado argentino es reducido, es pequeño. No podríamos sobrevivir solamente con lo que se vende en Argentina. Por eso, apenas surgió la editorial, casi de manera inmediata, buscamos internacionalizarnos. Sobre todo porque Argentina estaba a punto de caer en la gran crisis de 2001. Empezamos a editar en 1999 y al poco tiempo los problemas políticos, económicos y sociales eran muy fuertes. El desastre estaba por llegar. Cuando uno nace en el peor momento posible, hacia adelante sólo le queda mejorar, precisamente porque nació en circunstancias de dificultades extremas. Entonces empezamos a internacionalizarnos, a vender en España, a ir a las ferias de Frankfurt, Guadalajara, Madrid (o Barcelona), Londres. Y ese contacto nos permitió conocer rápidamente a la mayor parte de los editores del mundo que se interesan por la literatura latinoamericana y particularmente por la argentina. $\mathrm{Y}$ con ese grado de internacionalización y de venta afuera de Argentina complementamos nuestra venta. El 45\% de las ventas de nuestros libros se produce en Argentina, el 55\% restante se vende fuera del país.

¿Qué factores externos - sociales, políticos y económicos se pueden relacionar a las actividades de la editorial y como ellos influencian su trabajo? 
La influencia es inevitable porque pertenece a un lugar y a un tiempo y el contexto nos motiva, nos limita, nos condiciona y también nos apasiona. Este contexto es parte de nosotros. La llamada "realidad" funciona en un tiempo que es un tiempo online, que no es el de la literatura. El tiempo de la acción no es el mismo que el de la reflexión. Para la reflexión hay que estar en relativa calma, dedicarse a la lectura, escuchar, conversar, intercambiar, leer... y todo eso tiene un tiempo que no es el tiempo veloz del resto de la "realidad" política, social, económica, de las acciones y del mercado. Nuestro tiempo es un tiempo un poco más lento. Hay por supuesto una gran influencia de lo que pasa social y políticamente, eso que pasa afuera de una editorial. Pero, al mismo tiempo, hay una lógica propia, autonóma, una lógica que podríamos decir "de las ideas", de la literatura, que está en parte aislada del clima del momento, tal vez para pensar mejor ese momento en relación con el pasado y con lo que vendrá. Publicamos un libro porque creemos que es muy bueno ahora, y que lo será también en el próximo año y en siguientes. No tenemos el apuro de la emergencia. La literatura no genera urgencias. Genera placer, genera una particular intimidad, produce reflexión, conocimiento... y todo eso está fuera de la acción rápida que se impone desde el resto de la realidad. Entonces tiene otro tiempo, un tiempo de la lectura y del pensamiento, que son interdependientes.

\section{¿Veo que los nombres de los traductores están en la tapa y que se repiten.}

Exactamente, tenemos traductores muy fieles. Argentina es una gran productora de escuelas de traducción. No escuela en el sentido sistemático. A partir de Borges y otros grandes escritores y lectores-traductores que hubo en Argentina en los siglos XIX y XX, se logró un contacto con la literatura extranjera muy importante.

\section{¿Cómo se llega a los traductores?}

El mundo literario es un barrio pequeño y cuando uno trabaja hace durante más de treinta años en el campo editorial, los termina conociendo. Nos conocemos y tratamos de que sea una relación muy buena. Traducir es aislarse un poco del contexto, tener tiempo, tener el gusto por la lengua, tanto por la lengua de origen como por la lengua a la que se vierte el texto. Es muy importante. Si un traductor no dedica buena calidad de tiempo a su trabajo, no nos sirve como traductor.

\section{¿Qué autores argentinos son exportados a Brasil?}

Brasil nos está comprando algunos derechos de traducción. Por ejemplo, Antonio di Benedetto, un grandísimo escritor argentino, de quien hemos publicado su obra completa está siendo traducido integramente en Brasil.

Otro traducido en Brasil es un autor joven argentino, Alejandro López, de quien publicamos su primera novela La asesina de Lady Di, una novela divertidísima y muy bien 
escrita. Esta novela, que en castellano lleva tres ediciones, fue traducida al portugués y al inglés.

Estamos en contacto además con varias muy buenas editoriales brasileñas, de quienes estamos interesados en traducir a algunos de sus autores así como ellas tienen interés en autores pubicados por nosotros. También hemos conseguido que nuestros autores fueran traducidos al coreano, francés, inglés, italiano, hebreo, alemán.

Como editorial independiente nosotros preferimos ser los agentes literarios de nuestros autores, lo cual no es común, dado que suele ser la tarea de los agentes literarios.

* Mirna Soares Andrade viajou pelo intercâmbio PUC-Universidad de Rosario, coordenado pelo professor Karl Erik Schollhammer. 